\title{
ON- BOARD NON-ISOLATED BATTERY CHARGER FOR EV APPLICATION USING THE BDC
}

\author{
K. satish M. Tech student*1, B. Sankara prasad HOD and Associate professor ${ }^{2}$ \\ ${ }^{* 1,2}$ Electrical And Electronic Department, St. Theressa Institute of Engineering and Technology \\ *11ksatish.238@gmail.com,
}

*Corresponding Author: -

Email: ksatish.238@gmail.com,

\begin{abstract}
:
Non-isolated battery charger has been giving solutions in industrial applications so far. The survey has explained that generated torque in the motor must be zero to use the motor in charger circuit. Furthermore, this paper has been presented bidirectional converter for electric drive the proposed non-isolated integrated chargers are following advantages viz. Less price; structure is simple and very easy to control. Furthermore, the switching devices have been replaced with electronic switches therefore lower price of the charger compared to the other alternatives. Results have been presented using MATLAB/Simulink software
\end{abstract}

Key words: On-Board Battery Charger, DC/DC Boost converter, Bidirectional converter (BDC), electric vehicles (EVs), THD. 


\section{INTRODUCTION}

Internal combustion (IC) engines provide the traction power, in which the carbon generation is expected. So, in the present generation the most realistic solution for the transportation is the electric vehicles. This paper presents the on-board battery charger for such type of electric vehicle to avoid the environmental pollution and to avoid the dependency on conventional energy sources. This proposed on board technology avoids much time talking to refilling the storage system when compared with normal vehicle systems. Hybrid vehicles are developed to improve energy efficiency and to diminish emissions and they can also be surmounted the range limitations in electric automobile by employing two separate energy sources for propulsion. A plug-in hybrid electric vehicle (PHEV) is presented, that can be charged by connecting a plug to power source. There are two main types of battery chargers are presented: on-board and off-board type. To diminish the system quantity, heaviness, and price on the traction circuit motor, inverter, and sensors used in the charging circuit. Conventional On-board Battery Charger is discussed in section II. The proposed model is given and discussed in section III, control voltage principle is described in section IV, finally results and discussion part discussed in section V.

\section{CONVENTIONAL ON-BOARD BATTERY CHARGER}

So far there are many on board battery chargers are available for various applications including industrial applications. However, the existed topologies are not suitable for wide range of input conditions. Hence the IEEE standards give some topologies in order to overwhelm the aforementioned drawbacks and to fulfill the following needs for the on-board battery charging system. The first requirement is based on the above mentioned for a wider range of inputs; the output voltage must be stable controlled. The second requirement is based on the unity power factor (UPF); I.e., supply current should be within the standards of the UPF. Switching frequency should be applied to high frequency. Final one is keeping the mind of reliability, so in order to improve the reliability the proposed structure should be as small as possible

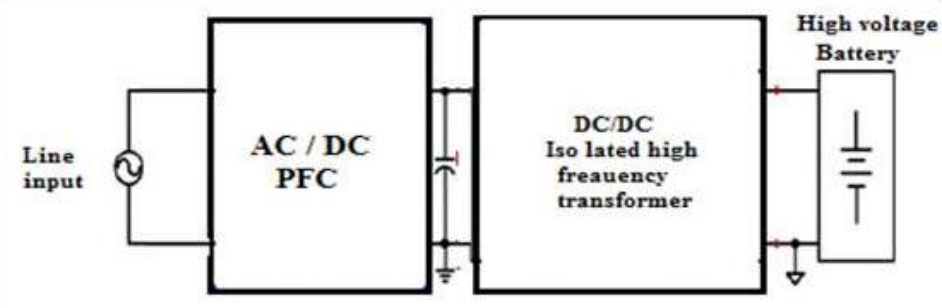

Figure 1: Conventional on-board charger- block diagram

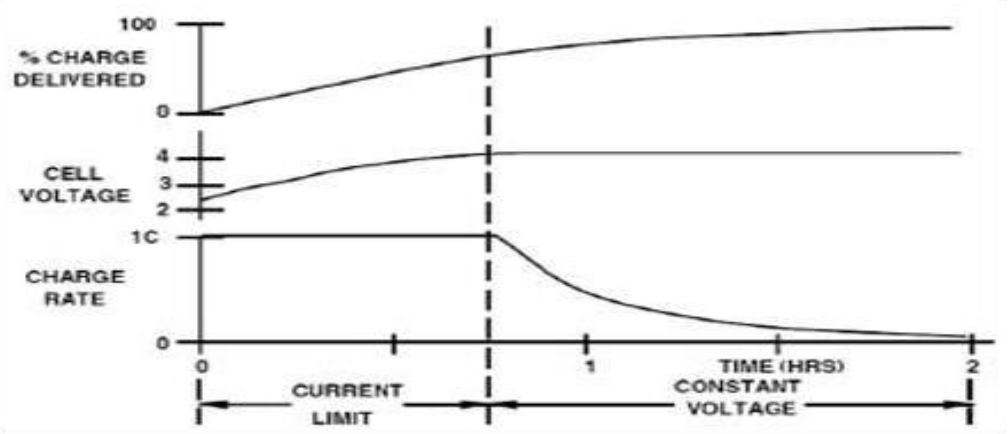

Figure 2: Constant voltage charge profile typical diagram

\section{III.PROPOSED MODEL}

Conventional hybrid electric vehicles usually have two different voltage levels [2]. Conventional loads such as lightning systems and vipers are connected to the low voltage bus. The increasing number of loads inspires the car industries to replace the $14 \mathrm{Vdc}$ bus with a $42 \mathrm{Vdc}$ bus supplied by a $36 \mathrm{~V}$ battery. By means of an isolated bidirectional DC/DC converter the high voltage and low voltage buses are tied together. Figure. 1 shows the proposed integrated battery charger.

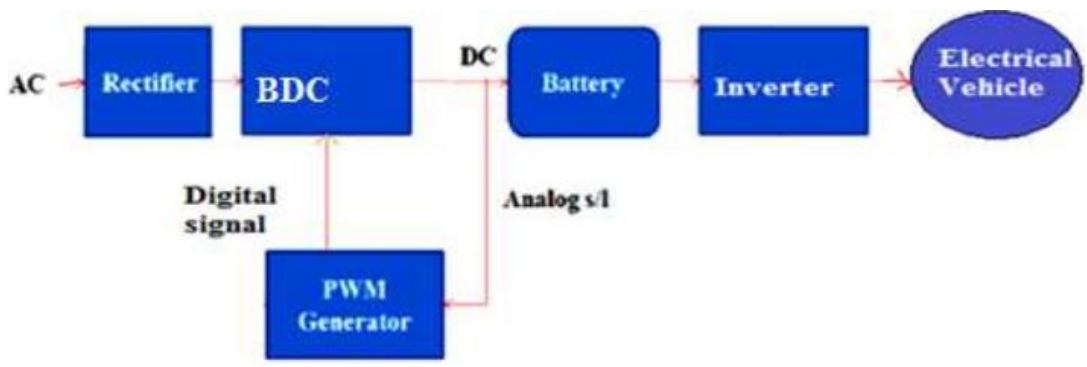

Figure 3: System diagram of proposed integrated charger

An inverter is placed to supply AC and to control the AC drive system. An integrated battery charger was proposed by Young-Joo Lee et al. 2009. The charger/converter is a non-isolated version with reduced number of inductors and current 
transducers for the single-phase input supply. The proposed integrated converter has three modes of operation: battery charging from the grid, boost operation to increase the battery voltage for normal traction operation and braking operation mode to recover braking power in the traction mode. The current mode PWM control is used in the system in which the detail control operation is explained.

\section{IV.NON-ISOLATED BI-DIRECTIONAL DC-DC CONVERTERS}

Basic buck and boost converters do not have the capability of bi-directional power flow. This constraint is mainly due to diodes, which averts the flow of current in the reverse direction. Usually, by replacing the diodes with controllable switches, this unidirectional structure can be converted into a bidirectional converter. As an example, Fig. 4 shows the conversion of unidirectional convertible into bidirectional converter by replacing the diodes. It is noteworthy that the resulted converter has the same structure in both cases. Fig. 6 illustrates the basic waveforms.

In the buck mode operation, i.e. Q1 is in an active state when the power is shifted from the high voltage side of the low voltage side, in this condition switch Q2 is kept off. In the boost mode, Q2 is a controlled switch when the power is shifted from LV to HV side and Q1 is kept off. Due to the inductor in the LV side causes lower ripple current, and in some applications this lower current ripple may be advantageous in charge and or discharging the batteries to get higher efficiency and longer lifetime
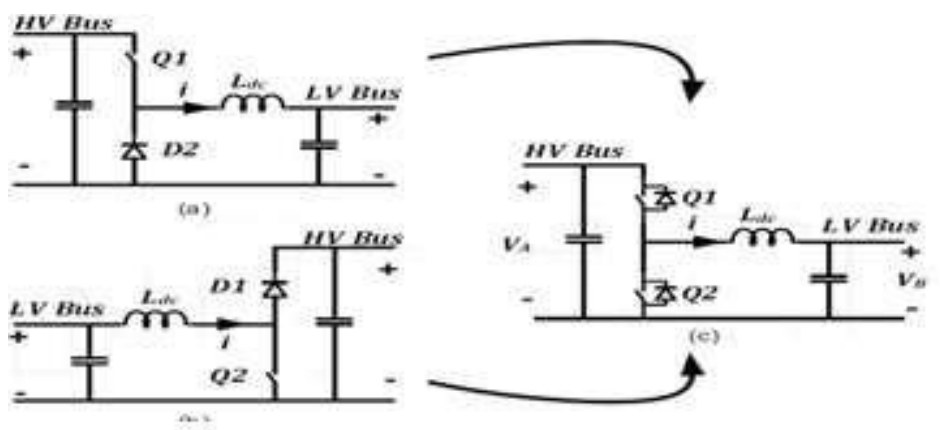

Figure.4. Conversion of any direction converter into bidirectional converter

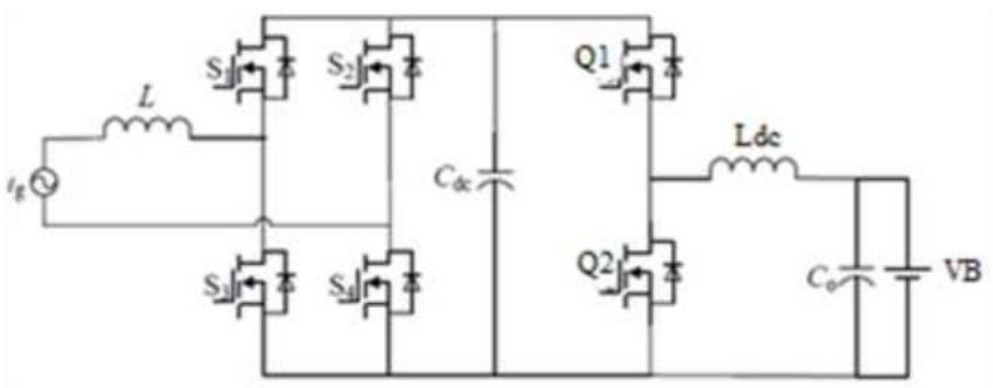

Figure.5. Non isolated BDC

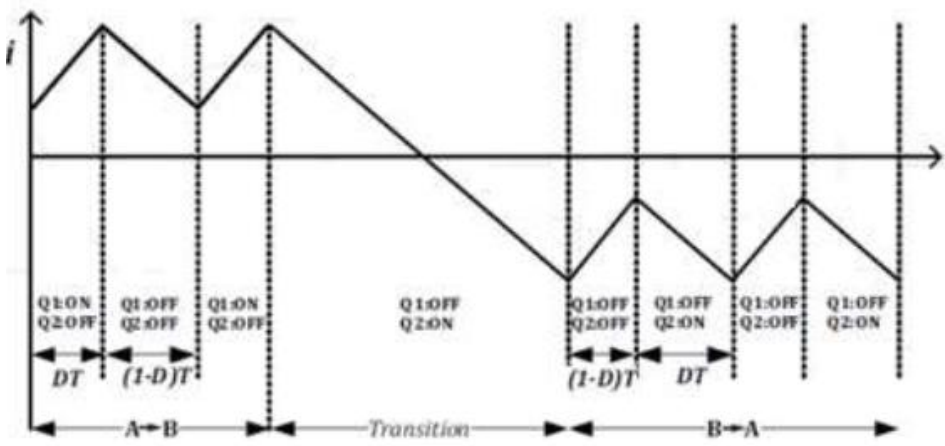

Figure. 6. Basic waveforms during charging and dis-charging using BDC

Bi-directional non-isolated DC-DC converters usually have advantages of very simple structure, high efficiency, high reliability; low cost, etc. numerous non-isolated bi-directional DC-DC converters that are reported in [11-14]. They can be classified into basic topologies such as Cuk converter Half-bridge converter, SEPIC/Luo converter. The half - bridge converter is the widely used topology, which operates either in Buck or in Boost mode. The cascaded half bridge and interleaved half bridge can be considered as derived topologies from the basic half bridge, and their performance can be evaluated based on the performance of the half bridge converter. Therefore, Half Bridge, Cuk and SEPIC/Luo converters are compared based on the example specification of bi-directional DC-DC converters in charging station.

The Buck mode equations are listed from (1) to (6): 


$$
\begin{aligned}
& \text { The switch duty ratio : } D_{s}=\frac{V_{B}}{V_{D}}=\frac{D_{L}}{2} \\
& \text { The effective duty ratio : } D_{L}=\frac{2 \cdot V_{B}}{V_{D}} \\
& \text { The inductor ripple current }: \frac{\nu_{d}-D_{s} \cdot\left(1-2 \cdot D_{s}\right)}{L \cdot\left(2 \cdot f_{s}\right)} \\
& \text { The inductor DC current }: \frac{2 \cdot I_{d}}{D_{L}}=\frac{I_{d}}{D_{s}} \\
& \text { The switch RMS current }=\frac{I_{d}}{D_{s}} \cdot \sqrt{D_{s}} \cdot \sqrt{1+\frac{r_{L}^{2}}{12}} \\
& \text { The diode RMS current }: \frac{I_{d}}{D_{c}} \cdot \sqrt{1-D_{s}} \cdot \sqrt{1+\frac{r_{L}^{2}}{12}}
\end{aligned}
$$

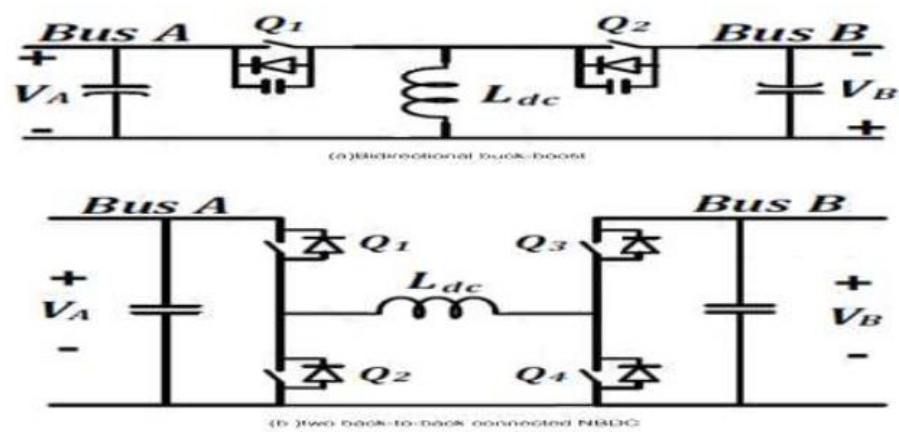

Figure.7. (a) Bi-directional Buck boost converter (b) back-to-back connect BDC. Boost mode equations are listed from (7) to (12)

$$
\begin{aligned}
& \text { The switch duty ratio : } D_{s}=1-\frac{1}{V_{D} / V_{B}}=\frac{1+D_{L}}{2} \\
& \text { The effective duty ratio : } D_{L}=1-\frac{2}{V_{D} / V_{B}} \\
& \text { The inductor ripple current }: \frac{V_{d} \cdot\left(1-D_{s}\right) \cdot\left(2 \cdot D_{s}-1\right)}{L \cdot\left(2 \cdot f_{S}\right)} \\
& \text { The inductor DC current }: \frac{2 \cdot I_{d}}{1-D_{L}}=\frac{I_{d}}{1-D_{s}}
\end{aligned}
$$

\section{CONTROLLING PRINCIPLE}

A DC-DC converter designed should present regulated output DC voltage under the input voltage conditions and load changing conditions. With the increase in temperature, time changes the component value gets changed. Hence the requirement of control output voltage on the closed loop basis using the negative feedback principle comes under consideration. Current mode control includes the extra loop to feedback inductor current signal. The conversion of feeding the current signal into its voltage analog is compared with the controlled voltage. This type of model is complex in hardware and this scheme in converters alters their dynamic behavior. Whereas simple hardware implementation is in the voltage control mode and is having flexibility.

This mode of control feedback the sensed output voltage, which is compared with the external reference voltage (VR), produces an error voltage $\left(\mathrm{V}_{\mathrm{e}}\right)$. This error voltage is corrected by the controller and the controlled voltage signal $\left(\mathrm{V}_{\mathrm{c}}\right)$ is sent to modulator where it is compared with the constant amplitude saw tooth wave form and generates the pulse width modulated control voltage signal $\left(\mathrm{V}_{\mathrm{m}}\right)$ and thus produces the required duty cycle. The duty ratio of generating PWM signal is dependent on the control voltage value. Fig.5 shows the block diagram of DC-DC converter with the close loop feedback system. 


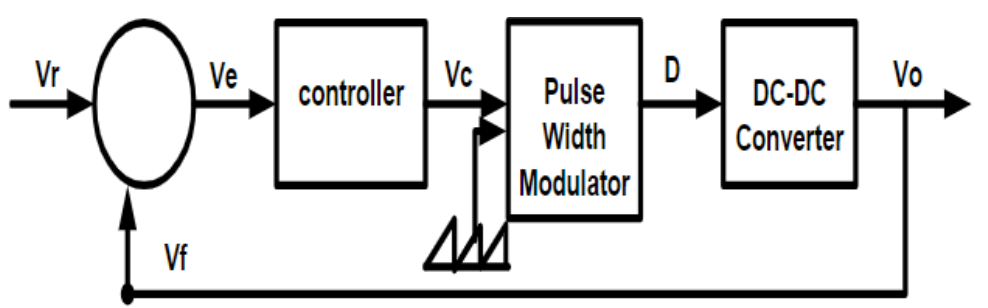

Figure.7. Voltage control scheme for DC-DC converter

\section{SIMULATION RESULTS}

In this paper, the proposed BDC converter is designed with 8.33 voltage gain. And then done small signal analysis for $\mathrm{BDC}$ converter to get transfer functions in both the modes and their transfer functions have been presented below.

BDC-Buck mode:

Transfer Function

$$
\frac{1177.4 s+1.14106 e 08}{s^{2}+8712 s+1.408 e 07}
$$

Transfer function with the modulator

$$
\frac{5887 s+5.703 e 08}{s^{2}+8712 s+1.408 e 07}
$$

Boost mode:

Transfer Function

Transfer function with the modulator

$$
\frac{-1.1922 e 04 s+0.6818 e 07}{s^{2}+492.2 s+1.936 e 05}
$$

$$
\frac{-5.961 e 04 s+3.409 e 07}{s^{2}+492.2 s+1.936 e 05}
$$

The Type-2 controller is designed to control the Bidirectional DC-DC converter in order to get the desired response with following specification $\mathrm{PM}=57^{\circ}$ and $\mathrm{GM}=14.7 \mathrm{~dB}$ and its transfer function, bode plot and gate signal generated through it are presented below

Controller

$$
=\frac{131300 s^{2}+\overline{9} .321 e 07 s+1.654 e 10}{s^{3}+25820 s^{2}+1.654 e 10}
$$

To verify the feasibility of the proposed system in real time implementation results have been verified with the help of Xilinx system interfaced MATLAB, Simulink as shown in fig. 8 to fig. 12.

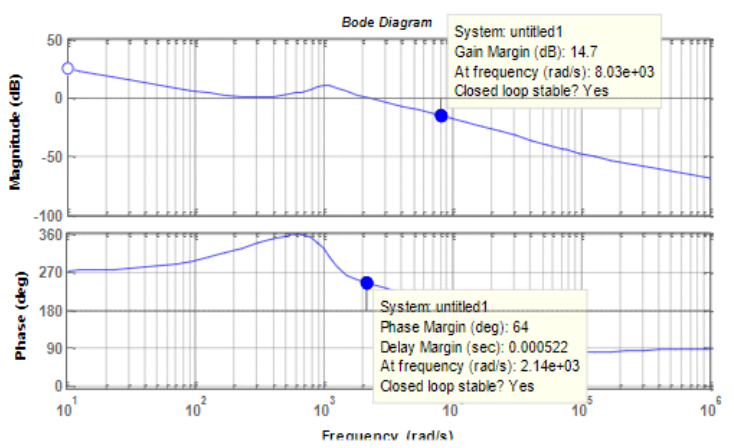

Fig.8. Bode plot of Boost converter loop gain with type-3 controller 


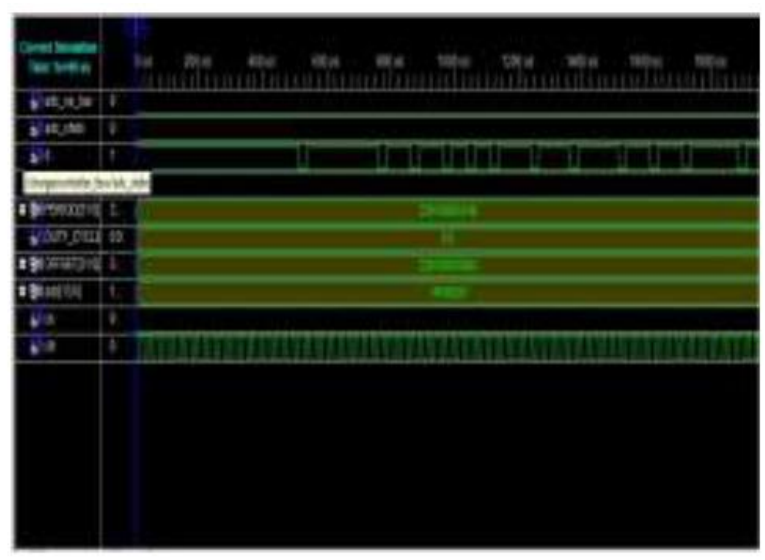

Fig.9. Firing pulses to BDC in boost mode

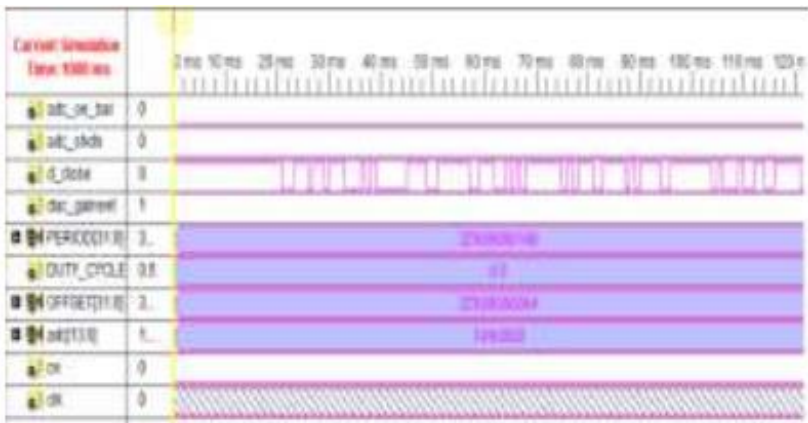

Figure: 10 Firing pulses to cuck mode
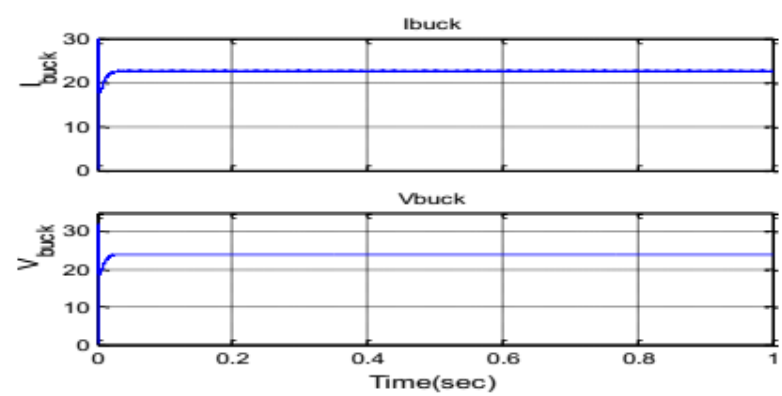

Figure: 11 Responses of $\mathrm{OBC}$ in $\mathrm{BDC}$ mode

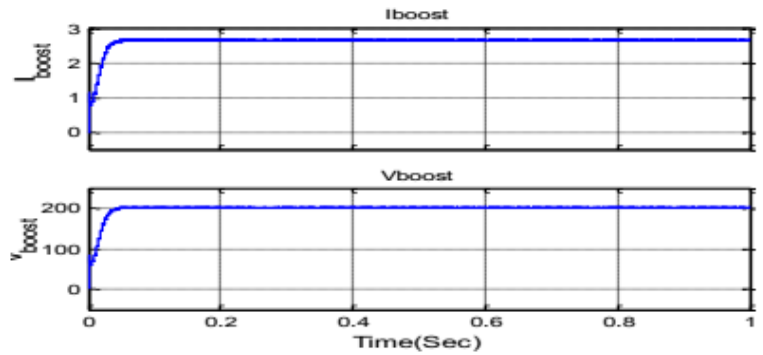

Figure: 12 Responses of BDC in buck mode 

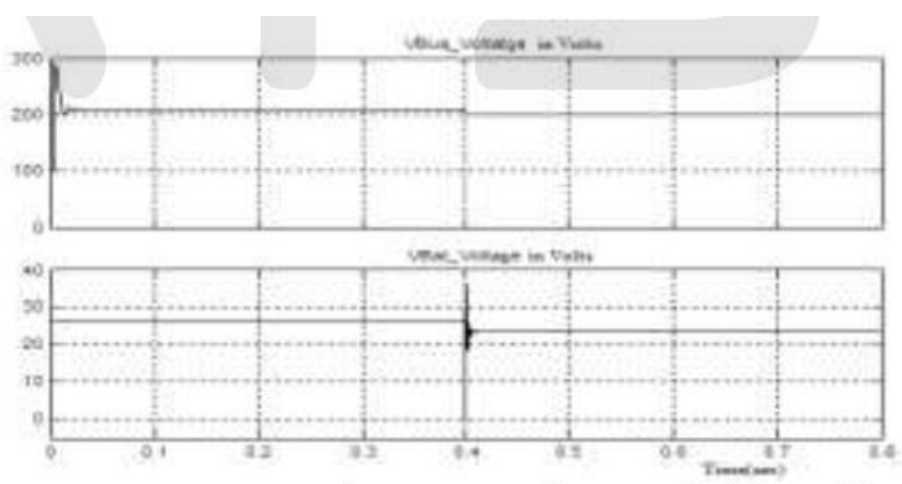

Figure:13 Voltage waveforms of either side (Bus side and battery side)

Battery and DC bus voltage and current are shown in following figure to check the charging and discharging of the battery.

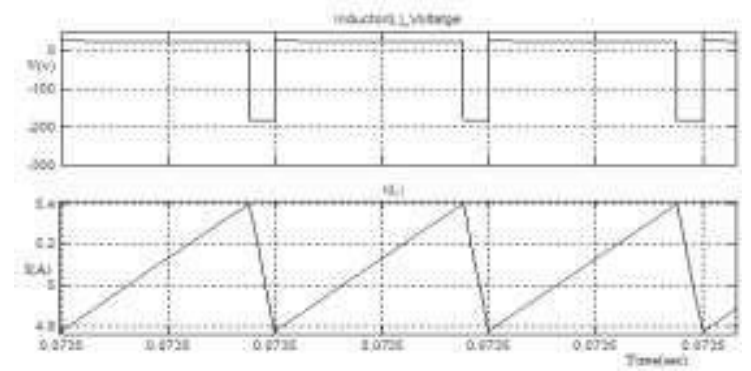

Figure:14 Inductor voltages and currents of BDC
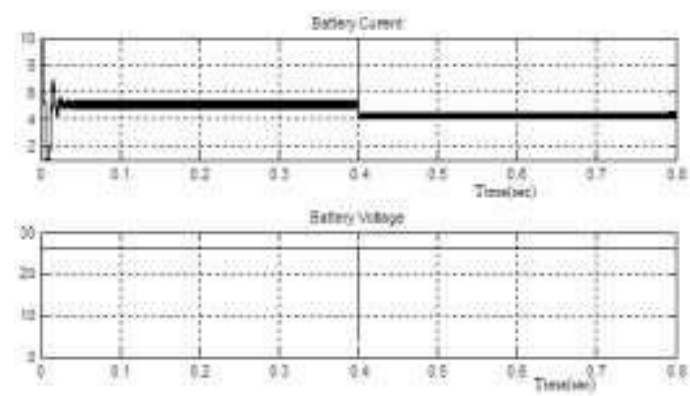

Figure:15 Battery side voltage and current

\section{CONCLUSION}

In this paper, the proposed BDC converter is designed with voltage gain of 8.33and also done the small signal analysis to derive transfer functions. Based on transfer function analysis, Type-2 controller is designed to control the clock converter with the specifications of $\mathrm{PM}=57^{\circ}$ and $\mathrm{GM}=14.7 \mathrm{~dB}$ and realized in the digital domain for the practical implementation of controller in FPGA. And got it verified the design converter is charging the battery at a faster rate due to its low switching and conduction losses. The dynamic response is good, which may raise issues for very high-power applications.

\section{References:}

[1].J. Cao and A. Emadi, “Batteries need electronics,” Industrial Electronics Magazine, IEEE, vol. 5, no. 1, pp. 27 -35, march 2011.

[2].M. Yilmaz and P. T. Krein, "Review of charging power levels and infrastructure for plug-in electric and hybrid vehicles," in Electric Vehicle Conference (IEVC), 2012 IEEE International, march 2012, pp. 1 -8.

[3].P. Krein, "Electrostatic discharge issues in electric vehicles," Industry Applications, IEEE Transactions on, vol. 32, no. 6 , pp. $1278-1284,1996$.

[4].Electric vehicle conductive charging system - Part1: General requirements, IEC 61851-1 Standard, First edition, 2001.

[5].Electric vehicle conductive charging system - Part21: Electric vehicle requirements for conductive connection to an a.c./d.c. supply, IEC 61851-21 Standard, First edition, 2001.

[6].S. Haghbin, S. Lundmark, M. Alakula, and O. Carlson, "Grid-connected integrated battery chargers in vehicle applications: Review and new solution,” Industrial Electronics, IEEE Transactions on, vol. 60, no. 2, pp. 459 -473, feb. 2013.

[7].S. Haghbin, K. Khan, S. Lundmark, M. Alakula, O. Carlson, M. Leksell, and O.Wallmark, "Integrated chargers for ev's and phev's: examples and new solutions," in Electrical Machines (ICEM), 2010 XIX International Conference on, sept. 2010, pp. $1-6$.

[8].S. Haghbin, M. Alakula, K. Khan, S. Lundmark, M. Leksell, O. Wallmark, and O. Carlson, "An integrated charger for plug-in hybrid electric vehicles based on a special interior permanent magnet motor," in Ve-hicle Power and 
Propulsion Conference (VPPC) Proceedings, in Lille, France, 2010.

[9].S. Haghbin, S. Lundmark, M. Alakula, and O. Carlson, "An isolated high-power integrated charger in electrifiedvehicle applications,” Vehicular Technology, IEEE Transactions on, vol. 60, no. 9, pp. 4115 -4126, nov. 2011.

[10]. [10] S. Haghbin and M. Alakula, "Elektrisk apparat innefattande drivsystem och elektrisk maskin med omkopplingsbar statorlindning," Swedish Patent Office, Patent no 1050607-9, Grant date: 14-02- 2012.

[11]. [11] M. Alakula and S. Haghbin, "Electrical apparatus comprising drive system and electrical machine with reconnectable stator winding," International Patent WO/2011/159241, Publication date 22 December 2011.

[12]. [12] M. Rawson and S. Kateley, "Electric vehicle charging equipment design and health and safety codes," California Energy Commission Report, 1998.

[13]. [13] C.-S. Wang, O. Stielau, and G. Covic, "Design considerations for a contactless electric vehicle battery charger," Industrial Electronics, IEEE Transactions on, vol. 52, no. 5, pp. 1308 - 1314, 2005.

[14]. [14] Devendra Patil, Mayank Sinha, Vivek Agarwal" A BDC Converter based Bridgeless Topology for High Power Factor Fast Battery Charger for Electric Vechicle Application” 978-1-4673-1408-4/12 @2012 IEEE 